\title{
Television watching and risk of colorectal adenoma
}

\author{
Y Cao ${ }^{1}$, N N Keum ${ }^{1}$, A T Chan ${ }^{2,3}$, C S Fuchs ${ }^{3,4}, \mathrm{~K} \mathrm{Wu}^{1,6}$ and E L Giovannucci ${ }^{*, 1,3,5,6}$ \\ ${ }^{1}$ Department of Nutrition, Harvard School of Public Health, 665 Huntington Avenue, Boston, MA 02115, USA; ${ }^{2}$ Division of \\ Gastroenterology, Massachusetts General Hospital, 55 Fruit Street, Boston, MA 02114, USA; ${ }^{3}$ Channing Division of Network \\ Medicine, Brigham and Women's Hospital and Harvard Medical School, 181 Longwood Avenue, Boston, MA 02115, USA; \\ ${ }^{4}$ Department of Medical Oncology, Dana-Farber Cancer Institute and Harvard Medical School, 450 Brookline Avenue, Boston, MA \\ 02115, USA and ${ }^{5}$ Department of Epidemiology, Harvard School of Public Health, 677 Huntington Avenue, Boston, MA 02115, USA
}

Background: Prolonged TV watching, a major sedentary behaviour, is associated with increased risk of obesity and diabetes and may involve in colorectal carcinogenesis.

Methods: We conducted a cross-sectional analysis among 31065 men with $\geqslant 1$ endoscopy in the Health Professionals Follow-up Study (1988-2008) to evaluate sitting while watching TV and its joint influence with leisure-time physical activity on risk of colorectal adenoma. Logistic regression was used to calculate odds ratios (ORs) and 95\% confidence intervals (Cls).

Results: Prolonged sitting while watching TV was significantly associated with increased risk of colorectal adenoma $(n=4280)$, and adjusting for physical activity or a potential mediator body mass index did not change the estimates. The ORs (95\% Cls) across categories of TV watching (0-6, 7-13, 14-20, and $21+\mathrm{h}$ per week) were 1.00 (referent), 1.09 (1.01-1.17), 1.16 (1.06-1.27), and 1.10 (0.97-1.25) (OR per 14-h per week increment $\left.=1.11 ; 95 \% \mathrm{Cl}: 1.04-1.18 ; P_{\text {trend }}=0.001\right)$. Compared with the least sedentary $(0-6 \mathrm{~h}$ per week of TV) and most physically active (highest quintile) men, the most sedentary ( $14+\mathrm{h}$ per week) and least active (lowest quintile) men had a significant increased risk of adenoma ( $\mathrm{OR}=1.25 ; 95 \% \mathrm{Cl}$ : 1.05-1.49), particularly for high-risk adenoma.

Conclusions: Prolonged TV viewing is associated with modest increased risk of colorectal adenoma independent of leisure-time physical activity and minimally mediated by obesity.

Sedentary behaviours, characterised by an energy expenditure $\leqslant 1.5$ METs (metabolic equivalent of task) while in a sitting or reclining posture, are increasingly prevalent and pervasive in modern society. These include sitting, lying down, reading, driving, watching TV, and other forms of screen-based entertainment. Although TV watching itself does not represent the entire sedentary behaviours, it is the most widespread leisure-time sedentary behaviour of adults in the United States and other western countries (Grontved and $\mathrm{Hu}, 2011$; Nielsen, 2011; Wijndaele et al, 2011) and is effective in ranking individuals by sedentary lifestyle (Fung et al, 2000; Owen et al, 2010). Indeed, epidemiologic studies have linked time spent watching TV with cardiometabolic biomarkers (Fung et al, 2000; Dunstan et al, 2005, 2007) and increased risk of obesity (Hu et al, 2003), diabetes
(Hu et al, 2001, 2003; Krishnan et al, 2009; Ford et al, 2010), cardiovascular disease (Warren et al, 2010; Stamatakis et al, 2011), and all-cause mortality (Stamatakis et al, 2011; Wijndaele et al, 2011), independent of physical activity levels. Stronger associations with TV viewing time than with occupational sitting time were also observed (Hu et al, 2003; Pinto Pereira et al, 2012). A higher likelihood of having eating patterns linked to commercial advertisement and food cues appearing on TV may partially explain the additional deleterious effect of prolonged TV viewing (Ainsworth et al, 1993).

Until recently, sedentary behaviours have not been extensively investigated in epidemiologic studies on cancer. A recent metaanalysis suggests that sedentary behaviours were associated with increased risk of colorectal, endometrial, and lung cancer (Schmid

*Correspondence: Dr EL Giovannucci; E-mail: egiovann@hsph.harvard.edu

${ }^{6}$ These authors contributed equally to this work.

Received 4 September 2014; revised 10 November 2014; accepted 4 December 2014; published online 15 January 2015

(c) 2015 Cancer Research UK. All rights reserved 0007-0920/15 
and Leitzmann, 2014). Different mechanisms are proposed and under investigation, but the role of sedentary behaviours in colorectal carcinogenesis is of particular interest as obesity and diabetes are established risk factors for colorectal cancer (Giovannucci et al, 1995, 2010; Larsson et al, 2005; Elwing et al, 2006; Giovannucci and Michaud, 2007). However, previous studies have been focused primarily on occupational sitting time (Gerhardsson et al, 1986; Arbman et al, 1993; Chow et al, 1993; Dosemeci et al, 1993; Weiderpass et al, 2003; Boyle et al, 2011), and the only study that examined TV watching found that time spent watching TV but not total time spent sitting was positively associated with colon cancer ( $\mathrm{RR}$ (relative risk) $=1.61,95 \% \mathrm{CI}$ : $1.14-2.27$ comparing $\geqslant 9 v s<3 \mathrm{~h}$ per day) among men (Howard et al, 2008).

To the best of our knowledge, no study has related sedentary behaviours to the occurrence of colorectal adenoma, the precursor of the majority of sporadic colorectal cancers (Lieberman et al, 2012). In this study, we evaluated the association of time spent sitting while watching TV as well as its joint influence with leisuretime physical activity on risk of colorectal adenoma among men who had at least one endoscopy between 1988 and 2008 in the Health Professionals Follow-up Study (HPFS). We also evaluated the influence of sitting at work/driving and other sitting at home.

\section{MATERIALS AND METHODS}

Study population. The HPFS is a cohort study of 51529 US male health professionals aged 40-75 years at enrolment in 1986. Participants have been mailed questionnaires every 2 years since baseline to collect data on demographics, lifestyle factors, medical history, and disease outcomes, and every 4 years to report update in dietary intake. The overall follow-up rate was $>94 \%$ (Rimm et al, 1990). In this analysis, we included participants without diagnosis of cancer (except nonmelanoma skin cancer), ulcerative colitis, or colorectal polyp before 1988. To reduce the potential for detection bias, we further restricted to 31716 men who reported having undergone at least one sigmoidoscopy or colonoscopy between 1988 and 2008. This study was approved by the institutional review board at the Harvard School of Public Health.

Ascertainment of colorectal adenoma cases and controls. On each biennial questionnaire, we asked whether participants had undergone sigmoidoscopy or colonoscopy; what the indications for these procedures were; whether colon or rectal polyps had been diagnosed in the past 2 years; and if they had the date of diagnosis. When a diagnosis was reported, we obtained informed consent to acquire medical records and pathology reports. Investigators blinded to any exposure information reviewed all records and extracted data on histological type, anatomic location, size, and number of the polyps.

Cases and controls were defined in each 2-year period: all newly diagnosed adenomas (including prevalent adenomas that may have been present for a long time and detected by current endoscopy as well as incident adenomas identified after a previous negative endoscopy, but not recurrent adenomas identified after positive endoscopies) were considered as cases, and all the participants who reported endoscopy but without diagnosis of adenoma were defined as controls. If more than one adenoma was diagnosed, the subject was classified according to the adenoma of the largest size and most advanced histological characteristics. Adenomas in the cecum, ascending colon, hepatic flexure, transverse colon, or splenic flexure were classified as being in the proximal colon. Adenomas in the descending or sigmoid colon were classified as distal and adenomas in the rectum or at the rectosigmoid junction were classified as rectal. We also grouped adenoma cases according to likelihood of developing advanced neoplasia during surveillance (high-risk: at least one adenoma $\geqslant 1 \mathrm{~cm}$ in diameter, or with advanced histology (tubulovillous or villous histologic features or high grade or severe dysplasia), or $\geqslant 3$ adenomas vs low-risk: other adenoma) (Lieberman et al, 2012), size (large: $\geqslant 1 \mathrm{~cm}$ vs small: $<1 \mathrm{~cm}$ ), histology (villous $v s$ tubular), and multiplicity $(\geqslant 3$ vs $<3)$.

Assessment of TV watching and other sedentary behaviours. Starting from 1988, participants reported their average weekly time spent watching TV (including videotapes) biennially. The 1988 questionnaire included six response categories (ranging from $0-1$ to $40+\mathrm{h}$ per week). Subsequent questionnaires included 13 response categories (ranging from 0 to $40+\mathrm{h}$ per week). We also assessed weekly hours of sitting at work, driving, and other sitting at home (including reading, eating, or at desk), respectively, using the same response categories as TV watching since 1990. To capture long-term sedentary behaviour, we calculated cumulative average hours of sitting (TV watching, at work/driving, and other sitting at home) up to the 2-year interval before the time of the current endoscopy. The main analysis of TV watching included 31065 men with information on TV watching.

Assessment of leisure-time physical activity. Participants reported average weekly time spent on the following activities biennially: walking, jogging, running, bicycling, calisthenics or use of a rowing machine, lap swimming, squash or racquetball, and tennis, and their usual walking pace. From these information, weekly energy expenditure in MET-h was calculated (Ainsworth et al, 1993). Our physical activity questions have been previously validated against physical activity diaries (Chasans-Taber et al, 1996).

Statistical analysis. We analysed sitting while watching TV (0-6, 7-13,14-20, and $21+\mathrm{h}$ per week) in relation to the risk of colorectal adenoma as the main analysis. We also evaluated whether sitting at work/driving, and other sitting at home was associated with adenoma risk. We then investigated the association between TV watching and risk of adenoma in the proximal, distal, and rectal colon. For proximal adenomas, we conducted sensitivity analysis excluding participants who only had sigmoidoscopy but no colonoscopy. In addition, we stratified by subtypes of adenoma.

To take into account that one person may have undergone multiple endoscopies between 1988 and 2008 and to handle timevarying exposure and covariates efficiently, Andersen-Gill data structure with a new record for each 2-year follow-up period during which a participant underwent an endoscopy was used. Exposure and covariates were set to their values at the time that the questionnaire was returned. Once a participant was diagnosed with adenoma, he was censored for all later follow-up cycles. Age and multivariate-adjusted logistic regressions for clustered data (PROC GENMOD) were used to account for repeated observations (i.e. multiple endoscopies) and calculate odds ratios (ORs) approximating relative risks. Test for trend was conducted using sitting time as a continuous variable. We controlled for the following potential confounders (cumulative updated when applicable): age in 5-year intervals; history of colorectal cancer in a first-degree relative (yes/no); personal history of diabetes (yes/no); height (meter in continuous); alcohol intake (g per day in categories: <5, 5-9.9, 10-14.9, 15-29.9, and 30+); smoking (pack-years in categories: never smoker, 1-4.9, 5-19.9, 20-39.9, and $40+$ ); regular aspirin use (yes/no); total calorie (kcal per day in quintiles); dietary variables including energy-adjusted total folate ( $\mu \mathrm{g}$ per day in quintiles); calcium intake (mg per day in quintiles); red and processed meat intake (servings per day in quintiles); time period of endoscopy (in 2-year interval to capture possible changes in adenoma detection rates); number of endoscopies (continuous); time in years since the most recent endoscopy (continuous); and reason for the current endoscopy (screening/symptoms/other). To fully assess whether observed 
associations may be explained by unhealthy diet, we adjusted for DASH (Dietary Approaches to Stop Hypertension Diet) score, instead of individual food/nutrient intake (total folate, calcium, and red and processed meat intake). DASH score is a composite score that features high intakes of fruit, vegetables, legumes, and nuts; moderate amounts of low-fat dairy products; and low amounts of animal protein and sweets (Fung et al, 2008). Adherence to the DASH diet is associated with reduced risk of colorectal cancer (Fung et al, 2010).

We additionally adjusted for leisure-time physical activity (MET-h per week in quintiles) to assess whether the influence of sedentary behaviours were independent of physical activity. We adjusted for body mass index (BMI, $\mathrm{kg} \mathrm{m}^{-2}$ in quintiles) to assess whether it mediates the association of interest. As BMI is not an accurate indicator of overweight and obesity in the elderly (Wannamethee et al, 2007), we conducted sensitivity analysis adjusting for waist circumference, a measure of abdominal obesity and a potential independent risk factor for colorectal cancer (Wang et al, 2008), among a subsample of men who reported their waist information in 1987 and 1996.

We examined if the association between TV watching and risk of adenoma differed by age, family history of colorectal cancer (yes/no), BMI ( <25, 25-29.9, and $30+\mathrm{kg} \mathrm{m}^{-2}$ ) and employment status (yes/no). Because employment likely influences the potential amount of time that can be spent sitting while watching TV, it could modify any association with adenoma. We also assessed the joint association of TV watching and physical activity by crossclassifying the two variables. We evaluated interaction by entering a product term of continuous TV watching and the above variables, and the $P$-value for interaction was determined by a Wald test.
To compare the influence of recent and long-term sedentary behaviour (the primary analysis) on risk of adenoma, we conducted sensitivity analysis using only the most recent TV viewing information before each endoscopy. Because adenoma cases in our primary analysis included both prevalent adenoma diagnosed at the first endoscopy and incident adenoma diagnosed after previous negative endoscopies, as exploratory analysis, we restricted to the first endoscopies to assess whether prolonged sitting was more associated with progression of adenoma. All the analyses were performed using SAS v. 9.3 (SAS Institute, Cary, NC, USA), and the statistical tests were two-sided and $P$-values $<0.05$ was considered statistically significant.

\section{RESULTS}

During 20 years of follow-up, we documented 4280 newly diagnosed adenomas among 31065 men who had at least one endoscopy between 1988 and 2008 and reported information on TV watching (Supplementary Table 1). We calculated the distribution of potential risk factors for adenomas according to categories of sitting while watching TV in 1998 (Table 1). Men who spent more time sitting while watching TV were older, had slightly higher BMI, and were more likely to have history of diabetes. These men also spent more time sitting at home reading, eating, or at desk, had higher intake of total energy, and red and processed meat. They were less likely to be employed and had lower intake of folate and calcium. Although men who spent more than $21 \mathrm{~h}$ sitting while watching TV per week engaged in less leisure-time physical activity compared with men who watched $0-6 \mathrm{~h}$ of TV per

Table 1. Age-standardised characteristics of participants according to time spent sitting watching television per week in 1998

\begin{tabular}{|c|c|c|c|c|}
\hline \multirow[b]{2}{*}{ Characteristic } & \multicolumn{4}{|c|}{ Sitting while watching TV (h per week) } \\
\hline & $0-6(n=4087)$ & $7-13(n=3692)$ & $14-20(n=1719)$ & $21+(n=706)$ \\
\hline Sitting while watching TV (h per week) & $4.0(1.8)$ & $10.1(2.0)$ & $16.7(1.9)$ & $25.6(4.3)$ \\
\hline Sitting at work/driving (h per week) & $15.8(11.5)$ & $16.8(11.3)$ & $16.3(11.4)$ & $16.0(11.9)$ \\
\hline Other sitting at home (h per week) ${ }^{a}$ & $8.3(5.8)$ & $10.8(6.3)$ & $12.2(7.2)$ & $13.8(8.2)$ \\
\hline Age (years) ${ }^{\mathbf{b}}$ & $63.4(8.5)$ & $64.5(8.8)$ & $65.5(8.9)$ & $67.5(8.5)$ \\
\hline Screening as indication for the current endoscopy (\%) & 84.5 & 83.5 & 90.2 & 78.8 \\
\hline Family history of colorectal cancer (\%) & 16.4 & 16.4 & 16.5 & 15.3 \\
\hline Personal history of diabetes (\%) & 5.7 & 6.2 & 7.5 & 8.5 \\
\hline Working full/part time (\%) & 69.9 & 66.1 & 60.1 & 57.1 \\
\hline Height $(\mathrm{cm})$ & $178(7)$ & $178(7)$ & $178(7)$ & $178(6)$ \\
\hline BMI $\left(\mathrm{kg} \mathrm{m}^{-2}\right)$ & $25.4(3.0)$ & $25.7(3.2)$ & $26.1(3.2)$ & $26.4(3.4)$ \\
\hline Waist circumference (in) & $38.0(3.8)$ & $38.5(3.9)$ & $39.0(4.0)$ & $39.4(4.3)$ \\
\hline Physical activity (MET-h per week) & $33.6(29.0)$ & $34.0(28.7)$ & $33.5(27.1)$ & $29.4(26.7)$ \\
\hline Regular aspirin user (\%) & 50.0 & 53.2 & 54.2 & 55.2 \\
\hline Pack-years among ever smokers & $21.5(17.4)$ & $23.1(17.5)$ & $23.6(18.3)$ & $28.2(19.9)$ \\
\hline Alcohol (g per day) & $9.9(11.6)$ & $11.1(12.7)$ & $11.6(13.5)$ & $12.3(15.6)$ \\
\hline Total calorie (kcal per day) & $1927(530)$ & $1954(517)$ & $1990(530)$ & $2015(530)$ \\
\hline Folate ( $\mu \mathrm{g}$ per day) & $576(233)$ & $560(223)$ & $544(212)$ & $519(213)$ \\
\hline Calcium (mg per day) & $963(358)$ & 937 (336) & 907 (320) & $898(320)$ \\
\hline Red meat (servings per day) & $6.2(4.8)$ & $6.8(4.9)$ & $7.7(5.1)$ & $7.9(5.2)$ \\
\hline Processed meat (servings per day) & $0.8(1.1)$ & $1.0(1.2)$ & $1.1(1.4)$ & $1.2(1.4)$ \\
\hline DASH score & $25.1(4.5)$ & $24.4(4.5)$ & $23.7(4.6)$ & $23.1(4.6)$ \\
\hline \multicolumn{5}{|c|}{$\begin{array}{l}\text { Abbreviations: } \mathrm{BMI}=\text { body mass index; DASH = DietaryApproaches to Stop Hypertension Diet; MET = metabolic equivalent of task. } \\
\text { a Sitting at home reading, eating, or at desk. } \\
\text { b All values other than age have been directly standardised to age distribution (in 5-year age group) of all the participants who had an endoscopy between } 1998 \text { and } 2000 \text {. Mean (s.d.) was } \\
\text { presented for continuous variables. }\end{array}$} \\
\hline
\end{tabular}


week, physical activity levels were similar across the other categories of TV watching.

More time spent sitting while watching TV was significantly associated with increased risk of colorectal adenoma in multivariate analysis (Table 2). When we adjusted for DASH score instead of folate, calcium, and red and processed meat, the ORs were essentially the same (data not shown). The results were similar after adjusting for physical activity as well as after further adjustment for BMI, suggesting that leisure-time physical activity did not confound and obesity minimally mediated the observed association. The ORs (95\% CIs) of adenoma across categories of TV watching (0-6, 7-13,14-20, and $21+\mathrm{h}$ per week) were 1.00 (referent), 1.09 (1.01-1.17), 1.16 (1.06-1.27), 1.10 (0.97-1.25), respectively $\left(P_{\text {trend }}=0.001\right)$. Each 14 -h increment of TV watching per week was associated with $11 \%$ increased risk of adenoma (OR $=1.11 ; 95 \%$ CI: 1.04-1.18). Sensitivity analysis controlling for waist circumference instead of BMI showed similar results (data not shown). Other sitting at home (reading, eating, or at desk) (OR per 14 -h per week increment $=1.08$; $95 \%$ CI: $1.02-1.16)$ but not sitting at work/driving was also associated with increased risk of adenoma. For the remaining analyses, we focused on sitting while watching TV and presented results for multivariate analysis adjusting for both physical activity and BMI.

Prolonged sitting while watching TV was associated more strongly with proximal and rectal adenoma compared with distal adenoma (Table 3). Excluding men who did not have colonoscopies minimally affected the risk estimates for proximal adenoma (Supplementary Table 2). Men who spent more time watching TV were slightly more likely to have high-risk compared with low-risk adenoma, which was primarily driven by $\geqslant 3$ adenomas (Table 4 ).

The positive association between TV watching and risk of adenoma was slightly stronger for men aged 65 years and above compared with men younger than 65 years, men without compared with men with family history of colorectal cancer, among those who were employed (full/part time) compared with retired/unemployed/disabled, and among normal and overweight men than for obese men, although interactions were not significant (Supplementary Table 3).

Leisure-physical activity was associated with lower risk of adenoma $\left(\mathrm{OR}_{\text {highest }}\right.$ vs lowest quintile: $0.87 ; 95 \%$ CI: $\left.0.78-0.97\right)$ independent of TV watching. In joint analysis, we observed minimal interaction of TV watching and physical activity levels with risk of adenoma $\left(P_{\text {interaction }}=0.98\right)$ (Table 5). Compared with men who were least sedentary (0-6h per week) and physically most active (highest quintile), those who were most sedentary (14 $+\mathrm{h}$ per week of TV watching) and least active (lowest quintile) had a significant increased risk for adenoma (OR $=1.25$; 95\% CI: 1.05-1.49). The joint association was more pronounced for highrisk $(\mathrm{OR}=1.29 ; 95 \% \mathrm{CI}: 1.00-1.66)$ than for low-risk adenoma $(\mathrm{OR}=1.06$; 95\% CI: $0.80-1.40)$.

The significant positive association between TV watching and risk of adenoma persisted when only the most recent information before each endoscopy was used instead of cumulative average (Supplementary Table 4). When we restricted to the first reported endoscopy for each man, the association remained similar, suggesting that sedentary lifestyle may be involved in both progression and initiation of colorectal adenoma (Supplementary Table 4).

\section{DISCUSSION}

In this prospective analysis nested in a large cohort of men, a sedentary lifestyle, primarily more time spent sitting while watching TV, was significantly associated with an increased risk

Table 2. ORs and $95 \% \mathrm{Cls}$ for TV watching, other sedentary behaviours, and risk of colorectal adenoma, HPFS 1988-2008

\begin{tabular}{|c|c|c|c|c|c|c|}
\hline \multicolumn{7}{|c|}{ Hours per week } \\
\hline & $0-6$ & $7-13$ & 14-20 & $21+$ & $P_{\text {trend }}$ & $\begin{array}{c}\text { Per 14-h per } \\
\text { week increment }\end{array}$ \\
\hline \multicolumn{7}{|l|}{ Sitting while watching TV } \\
\hline No. of cases $(n=4280)$ & 1534 & 1565 & 849 & 332 & & \\
\hline Age adjusted ${ }^{a}$ & 1.00 (ref.) & $1.12(1.04-1.20)$ & $1.22(1.12-1.33)$ & $1.17(1.03-1.32)$ & $<0.001$ & $1.16(1.09-1.23)$ \\
\hline Multivariate ${ }^{\mathbf{b}}$ & 1.00 (ref.) & $1.09(1.01-1.17)$ & $1.17(1.07-1.27)$ & $1.11(0.98-1.26)$ & 0.001 & $1.11(1.04-1.18)$ \\
\hline Multivariate $^{\text {b }}$ with physical activity ${ }^{c}$ & 1.00 (ref.) & $1.09(1.01-1.17)$ & $1.17(1.07-1.27)$ & $1.10(0.97-1.25)$ & 0.001 & $1.11(1.04-1.18)$ \\
\hline $\begin{array}{l}\text { Multivariate }{ }^{b} \text { with physical activity }{ }^{c} \text { and } \\
\text { BMI }^{c}\end{array}$ & 1.00 (ref.) & $1.09(1.01-1.17)$ & $1.16(1.06-1.27)$ & $1.10(0.97-1.25)$ & 0.001 & $1.11(1.04-1.18)$ \\
\hline \multicolumn{7}{|l|}{ Sitting at work/driving ${ }^{d}$} \\
\hline No. of cases $(n=4083)$ & 1097 & 994 & 742 & 1250 & & \\
\hline Age adjusted ${ }^{a}$ & 1.00 (ref.) & $0.99(0.90-1.08)$ & $1.04(0.94-1.15)$ & $0.97(0.88-1.06)$ & 0.12 & $0.97(0.93-1.01)$ \\
\hline Multivariate ${ }^{\mathbf{b}}$ & 1.00 (ref.) & $0.99(0.90-1.08)$ & $1.04(0.94-1.15)$ & $0.97(0.88-1.06)$ & 0.15 & $0.97(0.93-1.01)$ \\
\hline Multivariate $^{\mathrm{b}}$ with physical activity ${ }^{\mathrm{c}}$ & 1.00 (ref.) & $0.99(0.90-1.08)$ & $1.05(0.95-1.16)$ & $0.97(0.88-1.06)$ & 0.14 & $0.97(0.93-1.01)$ \\
\hline $\begin{array}{l}\text { Multivariate }{ }^{b} \text { with physical activity }{ }^{c} \text { and } \\
\text { BMI }^{c}\end{array}$ & 1.00 (ref.) & $0.99(0.90-1.08)$ & $1.05(0.94-1.16)$ & $0.97(0.88-1.06)$ & 0.14 & $0.97(0.93-1.01)$ \\
\hline \multicolumn{7}{|l|}{ Other sitting at home ${ }^{d}$} \\
\hline No. of cases $(n=4083)$ & 1497 & 1637 & 675 & 274 & & \\
\hline Age adjusted ${ }^{a}$ & 1.00 (ref.) & $1.08(1.00-1.16)$ & $1.14(1.04-1.25)$ & $1.05(0.92-1.20)$ & 0.01 & $1.09(1.02-1.16)$ \\
\hline Multivariate ${ }^{\mathbf{b}}$ & 1.00 (ref.) & $1.07(0.99-1.15)$ & $1.12(1.02-1.24)$ & $1.03(0.90-1.19)$ & 0.04 & $1.07(1.01-1.15)$ \\
\hline Multivariate $^{\mathbf{b}}$ with physical activity & 1.00 (ref.) & $1.08(1.00-1.16)$ & $1.13(1.03-1.25)$ & $1.05(0.91-1.20)$ & 0.02 & $1.08(1.01-1.16)$ \\
\hline $\begin{array}{l}\text { Multivariate }{ }^{b} \text { with physical activity }{ }^{c} \text { and } \\
\text { BMI }^{c}\end{array}$ & 1.00 (ref.) & $1.08(1.00-1.16)$ & $1.14(1.03-1.25)$ & $1.05(0.92-1.21)$ & 0.02 & $1.08(1.02-1.16)$ \\
\hline \multicolumn{7}{|c|}{ 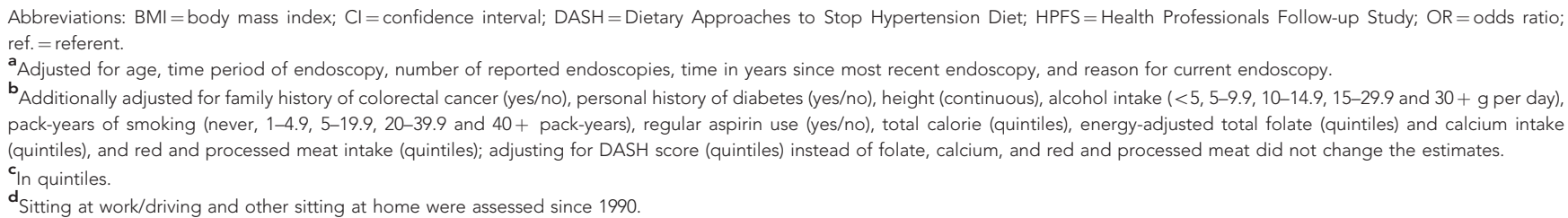 } \\
\hline
\end{tabular}


Table 3. ORs and $95 \% \mathrm{Cls}$ for TV watching and risk of adenoma by anatomic location, HPFS 1988-2008

\begin{tabular}{|c|c|c|c|c|c|c|}
\hline & \multicolumn{4}{|c|}{ Sitting while watching (h per week) } & \multirow[b]{2}{*}{$P_{\text {trend }}$} & \multirow[b]{2}{*}{$\begin{array}{c}\text { Per } 14-h \text { per } \\
\text { week increment }\end{array}$} \\
\hline & $0-6$ & $7-13$ & $14-20$ & $21+$ & & \\
\hline \multicolumn{7}{|l|}{ Proximal colon } \\
\hline No. of cases $(n=2257)$ & 824 & 809 & 445 & 179 & & \\
\hline Age adjusted $^{\mathbf{a}}$ & 1.00 (ref.) & $1.07(0.97-1.18)$ & $1.22(1.08-1.37)$ & $1.22(1.03-1.44)$ & $<0.001$ & $1.24(1.09-1.42)$ \\
\hline Multivariate & 1.00 (ref.) & $1.04(0.94-1.15)$ & $1.17(1.04-1.32)$ & $1.17(0.98-1.38)$ & 0.005 & $1.13(1.04-1.24)$ \\
\hline Multivariate $^{\mathrm{b}}$ with physical activity and BMI & 1.00 (ref.) & $1.04(0.94-1.15)$ & $1.16(1.03-1.31)$ & $1.15(0.97-1.37)$ & 0.01 & $1.12(1.03-1.23)$ \\
\hline \multicolumn{7}{|l|}{ Distal colon } \\
\hline No. of cases $(n=2092)$ & 738 & 781 & 402 & 171 & & \\
\hline Age adjusted ${ }^{\mathrm{a}}$ & 1.00 (ref.) & $1.16(1.05-1.29)$ & $1.17(1.03-1.32)$ & $1.19(1.00-1.42)$ & 0.003 & $1.14(1.05-1.24)$ \\
\hline Multivariate ${ }^{\mathbf{b}}$ & 1.00 (ref.) & $1.12(1.01-1.24)$ & $1.09(0.96-1.24)$ & $1.08(0.99-1.17)$ & 0.10 & $1.08(0.99-1.17)$ \\
\hline Multivariate ${ }^{\mathbf{b}}$ with physical activity and BMI & 1.00 (ref.) & $1.12(1.01-1.24)$ & $1.09(0.96-1.24)$ & $1.10(0.93-1.31)$ & 0.11 & $1.07(0.98-1.17)$ \\
\hline \multicolumn{7}{|l|}{ Rectum } \\
\hline No. of cases $(n=734)$ & 250 & 266 & 161 & 57 & & \\
\hline Age adjusted $^{\mathrm{a}}$ & 1.00 (ref.) & $1.17(0.99-1.40)$ & $1.38(1.13-1.69)$ & $1.18(0.88-1.58)$ & 0.004 & $1.22(1.07-1.39)$ \\
\hline Multivariate ${ }^{\mathbf{b}}$ & 1.00 (ref.) & $1.13(0.95-1.35)$ & $1.30(1.06-1.60)$ & $1.10(0.82-1.48)$ & 0.03 & $1.16(1.01-1.33)$ \\
\hline Multivariate ${ }^{\mathbf{b}}$ with physical activity and BMI & 1.00 (ref.) & $1.13(0.95-1.35)$ & $1.30(1.06-1.59)$ & $1.10(0.82-1.48)$ & 0.04 & \\
\hline \multicolumn{7}{|c|}{$\begin{array}{l}\text { Abbreviations: } \mathrm{BMI}=\text { body mass index; } \mathrm{Cl}=\text { confidence interval; } \mathrm{HPFS}=\text { Health Professionals Follow-up Study; OR=odds ratio; ref. = referent. } \\
{ }^{\mathrm{a}} \text { Adjusted for age, time period of endoscopy, number of reported endoscopies, time since most recent endoscopy, and reason for current endoscopy. } \\
{ }^{\mathrm{b}} \text { Additionally adjusted for family history of colorectal cancer, history of diabetes, height, alcohol intake, smoking, aspirin use, total calorie, folate, calcium intake, and red and processed meat } \\
\text { intake. }\end{array}$} \\
\hline
\end{tabular}

for colorectal adenoma. This association appeared independent of levels of leisure-time physical activity and minimally mediated by BMI. The association was more pronounced for rectal and proximal compared with distal adenoma, and slightly stronger for high-risk than for low-risk adenoma, driven by multiple adenomas. To the best of knowledge, our study is the first to link sedentary behaviour and a precursor of cancer.

Our findings indicate the potential importance of reducing time spent sedentary, in particular TV viewing time, in addition to promoting physical activity in the prevention of colorectal neoplasia. In particular, being less sedentary and more active reduce primarily risk of high-risk adenoma, which is more likely to progress to colorectal cancer and serves as the major target in screening endoscopies (Winawer and Zauber, 2002; Regula et al, 2006). Our observed weaker and null association between other sitting at home (reading, eating, or at desk), sitting at work/driving, and risk of colorectal adenoma, respectively, were consistent with a recent meta-analysis that, for colon cancer, the RR was higher for TV watching $(\mathrm{RR}=1.54)$ than for time spent sitting at work $(\mathrm{RR}=1.24)$, comparing the highest $v$ s lowest levels of sedentary time (Schmid and Leitzmann, 2014). The reasons for these differences across sedentary pursuits were unclear but may be related to measurement errors as well as additional link between TV and unhealthy diet ( $\mathrm{Hu}$ et al, 2003; Owen et al, 2010).

There are several plausible mechanisms through which sedentary behaviour may increase the risk of colorectal neoplasia. Obesity may represent an intermediate step in the causal pathway (Lynch, 2010). However, in our multivariate analysis, the odds ratio estimates were hardly changed after adjustment for BMI or waist circumference. Another hypothesis is that prolonged TV watching was associated with increased consumption of unhealthy food (Hu et al, 2001, 2003); however, in our study, the positive significant association persisted after adjusting for individual food/ nutrient intake (red and processed meat, folate, and calcium) or composite DASH score. Other mechanisms have been postulated. Hyperinsulinaemia and possibly hyperglycaemia may promote colon carcinogenesis (Giovannucci, 1995, 2007). A meta-analysis of 10 cross-sectional studies showed that, comparing the highest level of sedentary behaviour to the lowest, greater time spent sedentary increased the risk of metabolic syndrome by $73 \%$ (Edwardson et al, 2012). A prospective analysis among 376 middle-aged adults suggested that baseline sedentary behaviour (defined by heart rate observations below an individually predetermined threshold) was independently associated with higher log fasting plasma insulin at follow-up (Helmerhorst et al, 2009). In cross-sectional studies, sedentary behaviour was also positively associated with insulin (Gustat et al, 2002), insulin resistance (Balkau et al, 2008; Schmidt et al, 2008), and 2-h glucose (Healy et al, 2007). Inflammation (Fung et al, 2000) and loss of muscle contractile activity that leads to suppressed lipoprotein lipase activity and glucose uptake (Hamilton et al, 2007) may also be involved in the link between sitting time and adenoma/cancer.

Our observation that prolonged sitting while watching TV was associated more strongly with proximal and rectal adenoma compared with distal adenoma requires confirmation by other studies. Indeed, literature concerning physical activity and colorectal cancer by anatomical subsites were inconsistent (Robsahm et al, 2013) and limited evidence suggested that sedentary behaviour may also differentially affect colon carcinogenesis by subsite (Boyle et al, 2011). Of note, identification of potential differential associations between an exposure and risk of colorectal adenoma/cancer by anatomic subsite could provide more insight into the colorectal carcinogenic mechanisms. For example, cigarette smoking is associated with higher risk of CIMP (CpG island methylator phenotype) high (Samowitz et al, 2006; Curtin et al, 2009; Limsui et al, 2010; Nishihara et al, 2013), MSI (microsatellite instability) high (Slattery et al, 2000; Curtin et al, 2009; Poynter et al, 2009; Limsui et al, 2010; Nishihara et al, 2013), and BRAF- (v-raf murine sarcoma viral oncogene homolog B1) mutated (Samowitz et al, 2006; Curtin et al, 2009; Limsui et al, 2010; Rozek et al, 2010; Nishihara et al, 2013) colorectal cancers, which occur more frequently in the proximal colon. In particular, if our observed stronger association between sitting while watching TV and proximal adenoma were true, decreasing sedentary behaviour may be particularly beneficial for the prevention of proximal adenomas/cancers, which are less detectable and more likely to be missed even in colonoscopies (Lieberman et al, 2012).

Strengths of our study include the ability to capture long-term sedentary behaviour, minimise measurement errors through asking time spent sitting watching TV explicitly while excluding TV viewing coupled with other non-sedentary activities (e.g. cooking, on treadmills), and control for a variety of potential confounders and mediators. In addition, although the average hours of sitting watching TV (10 h per week) was lower than the national estimates 
Table 4. ORs and $95 \% \mathrm{Cls}$ for TV watching and risk of adenoma by subtypes, HPFS 1988-2008

Sitting while watching TV (h per week)

\begin{tabular}{|c|c|c|c|c|c|c|c|}
\hline & $0-6$ & 7-13 & $14-20$ & $21+$ & $P_{\text {trend }}$ & $\begin{array}{l}\text { Per 14-h } \\
\text { per week } \\
\text { increment }\end{array}$ & $\begin{array}{l}\text { Physical } \\
\text { activity }^{\text {a }}\end{array}$ \\
\hline \multicolumn{8}{|l|}{ High risk ${ }^{b}$} \\
\hline No. of cases $(n=1833)$ & 646 & 661 & 363 & 163 & & & \\
\hline Age adjusted ${ }^{c}$ & 1.00 (ref.) & $1.10(0.99-1.23)$ & $1.18(1.03-1.35)$ & $1.24(1.04-1.48)$ & $<0.001$ & $1.17(1.07-1.28)$ & \\
\hline Multivariate ${ }^{\mathbf{d}}$ & 1.00 (ref.) & $1.07(0.96-1.19)$ & $1.11(0.98-1.27)$ & $1.16(0.97-1.38)$ & 0.02 & $1.12(1.02-1.22)$ & \\
\hline Multivariate ${ }^{\mathbf{d}}$ with physical activity and BMI & 1.00 (ref.) & $1.07(0.95-1.19)$ & $1.11(0.97-1.27)$ & $1.14(0.95-1.37)$ & 0.03 & $1.11(1.01-1.21)$ & $0.78(0.67-0.91)$ \\
\hline \multicolumn{8}{|l|}{ Low risk } \\
\hline No. of cases $(n=1606)$ & 592 & 595 & 309 & 110 & & & \\
\hline Age adjusted ${ }^{c}$ & 1.00 (ref.) & $1.11(0.99-1.25)$ & $1.20(1.05-1.39)$ & $1.09(0.89-1.34)$ & 0.02 & $1.12(1.02-1.24)$ & \\
\hline Multivariate ${ }^{d}$ & 1.00 (ref.) & $1.09(0.97-1.22)$ & $1.16(1.01-1.34)$ & $1.05(0.85-1.30)$ & 0.09 & 1.09 (0.99-1.21) & \\
\hline Multivariate ${ }^{\mathbf{d}}$ with physical activity and BMI & 1.00 (ref.) & $1.09(0.97-1.22)$ & $1.16(1.01-1.34)$ & $1.05(0.85-1.30)$ & 0.09 & $1.09(0.99-1.21)$ & $1.01(0.85-1.19)$ \\
\hline \multicolumn{8}{|l|}{ Large } \\
\hline No. of cases $(n=1271)$ & 445 & 470 & 252 & 104 & & & \\
\hline Age adjusted ${ }^{c}$ & 1.00 (ref.) & $1.14(1.00-1.30)$ & $1.18(1.01-1.38)$ & $1.13(0.91-1.41)$ & 0.01 & $1.14(1.03-1.27)$ & \\
\hline Multivariate ${ }^{d}$ & 1.00 (ref.) & $1.09(0.96-1.25)$ & $1.11(0.94-1.30)$ & $1.05(0.84-1.31)$ & 0.16 & $1.08(0.97-1.21)$ & \\
\hline Multivariate ${ }^{d}$ with physical activity and BMI & 1.00 (ref.) & $1.10(0.96-1.25)$ & $1.10(0.94-1.30)$ & $1.05(0.84-1.31)$ & 0.17 & $1.08(0.97-1.21)$ & $0.75(0.62-0.91)$ \\
\hline \multicolumn{8}{|l|}{ Small } \\
\hline No. of cases $(n=2626)$ & 943 & 948 & 532 & 203 & & & \\
\hline Age adjusted ${ }^{c}$ & 1.00 (ref.) & $1.12(1.02-1.22)$ & $1.28(1.15-1.43)$ & $1.23(1.05-1.44)$ & $<0.001$ & $1.19(1.10-1.29)$ & \\
\hline Multivariate ${ }^{d}$ & 1.00 (ref.) & $1.09(1.00-1.20)$ & $1.24(1.11-1.38)$ & 1.19 (1.01-1.39) & $<0.001$ & $1.16(1.07-1.25)$ & \\
\hline Multivariate ${ }^{d}$ with physical activity and BMI & 1.00 (ref.) & $1.09(1.00-1.20)$ & $1.24(1.10-1.38)$ & $1.18(1.01-1.39)$ & $<0.001$ & $1.16(1.07-1.25)$ & $0.94(0.82-1.07)$ \\
\hline \multicolumn{8}{|l|}{ Villous } \\
\hline No. of cases $(n=852)$ & 294 & 310 & 175 & 73 & & & \\
\hline Age adjusted ${ }^{c}$ & 1.00 (ref.) & $1.13(0.96-1.33)$ & $1.21(1.00-1.46)$ & $1.14(0.88-1.49)$ & 0.12 & $1.11(0.98-1.26)$ & \\
\hline Multivariate ${ }^{d}$ & 1.00 (ref.) & $1.11(0.95-1.31)$ & $1.16(0.96-1.41)$ & $1.10(0.84-1.43)$ & 0.28 & $1.07(0.94-1.22)$ & \\
\hline Multivariate ${ }^{d}$ with physical activity and BMI & 1.00 (ref.) & $1.11(0.94-1.30)$ & $1.15(0.95-1.40)$ & $1.08(0.83-1.40)$ & 0.37 & $1.06(0.93-1.21)$ & $0.85(0.68-1.06)$ \\
\hline \multicolumn{8}{|l|}{ Tubular } \\
\hline No. of cases $(n=2511)$ & 932 & 929 & 471 & 179 & & & \\
\hline Age adjusted ${ }^{c}$ & 1.00 (ref.) & $1.10(1.00-1.20)$ & $1.15(1.02-1.29)$ & 1.09 (0.93-1.29) & 0.005 & $1.12(1.04-1.21)$ & \\
\hline Multivariate ${ }^{\mathbf{d}}$ & 1.00 (ref.) & $1.06(0.96-1.16)$ & $1.08(0.97-1.22)$ & $1.03(0.87-1.21)$ & 0.11 & $1.07(0.98-1.16)$ & \\
\hline Multivariate ${ }^{\mathbf{d}}$ with physical activity and BMI & 1.00 (ref.) & $1.06(0.97-1.17)$ & $1.08(0.97-1.22)$ & $1.02(0.87-1.21)$ & 0.12 & $1.07(0.98-1.16)$ & $0.89(0.78-1.02)$ \\
\hline \multicolumn{8}{|l|}{$\geqslant 3$ Adenomas } \\
\hline No. of cases $(n=600)$ & 206 & 218 & 115 & 61 & & & \\
\hline Age adjusted ${ }^{c}$ & 1.00 (ref.) & $1.14(0.94-1.38)$ & $1.18(0.94-1.49)$ & $1.47(1.11-1.97)$ & 0.004 & $1.25(1.08-1.46)$ & \\
\hline Multivariate ${ }^{\mathbf{d}}$ & 1.00 (ref.) & $1.08(0.89-1.31)$ & $1.10(0.87-1.38)$ & $1.35(1.01-1.80)$ & 0.04 & $1.18(1.01-1.38)$ & \\
\hline Multivariate ${ }^{\mathbf{d}}$ with physical activity and BMI & 1.00 (ref.) & $1.08(0.89-1.31)$ & $1.09(0.86-1.37)$ & $1.30(0.98-1.74)$ & 0.07 & $1.16(0.99-1.36)$ & $0.71(0.55-0.92)$ \\
\hline \multicolumn{8}{|l|}{ 1-2 Adenomas } \\
\hline No. of cases $(n=3613)$ & 1307 & 1319 & 717 & 270 & & & \\
\hline Age adjusted ${ }^{c}$ & 1.00 (ref.) & $1.11(1.03-1.20)$ & $1.22(1.11-1.34)$ & $1.13(0.98-1.29)$ & $<0.0001$ & $1.14(1.07-1.22)$ & \\
\hline Multivariate ${ }^{\mathbf{d}}$ & 1.00 (ref.) & $1.08(1.00-1.17)$ & $1.17(1.06-1.28)$ & $1.08(0.94-1.23)$ & 0.005 & $1.10(1.03-1.18)$ & \\
\hline Multivariate ${ }^{d}$ with physical activity and BMI & 1.00 (ref.) & $1.09(1.00-1.18)$ & $1.17(1.06-1.29)$ & $1.08(0.94-1.24)$ & 0.005 & $1.10(1.03-1.18)$ & $0.90(0.81-1.01)$ \\
\hline \multicolumn{8}{|c|}{ 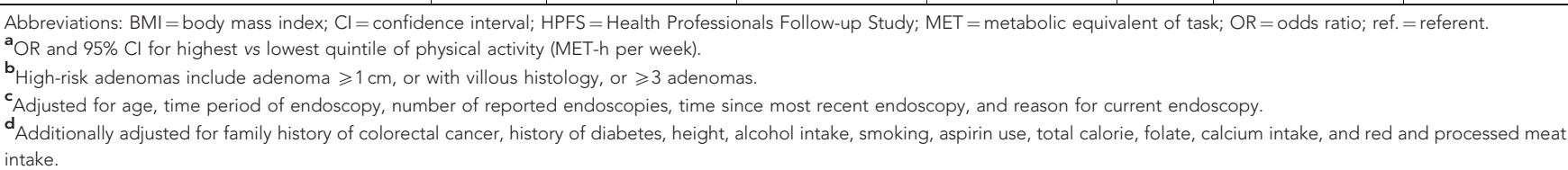 } \\
\hline
\end{tabular}

(34h per week in adults aged 50-64 years) (Nielsen, 2011), a widespread distribution of TV viewing time in our study (an average of $4 \mathrm{~h}$ per week among the least and $26 \mathrm{~h}$ per week in the most sedentary men) allowed us to assess the potential health benefit of a less sedentary lifestyle. Our study also had several limitations. First, we did not assess time of standing at home/work, which similarly requires low energy expenditure, but physically different from sitting by involving isometric contraction of the antigravity (postural) muscles (Hamilton et al, 2008; Owen et al, 2010). Whether standing could ameliorate the increased risk of colorectal adenoma and other chronic outcomes associated with too much sitting requires more investigation. In addition, time spent sitting at computer, an increasingly prevalent sedentary behaviour in modern society, was not assessed in our cohort.
Second, we only included participants who reported having undergone an endoscopy. However, as adenomas are largely asymptomatic, misclassification of outcome is likely nondifferential, that is, not related to sedentary behaviours, and thus influence of such bias if any is likely to be small. Moreover, selfreport of endoscopies were reliable in our cohort. A previous review of the medical records obtained from a random sample of 200 patients who reported a negative endoscopic result confirmed the absence of adenomas in all cases. In addition, measurement errors associated with recall of sedentary behaviours as well as potential confounders from the biennial questionnaires were likely; however, they would be non-differential to adenoma diagnosis. Possibility of residual confounding, especially from physical activity, could not be ruled out even though our leisure-time 
Table 5. Joint analysis of TV watching and leisure-time physical activity on risk of adenoma, HPFS 1988-2008

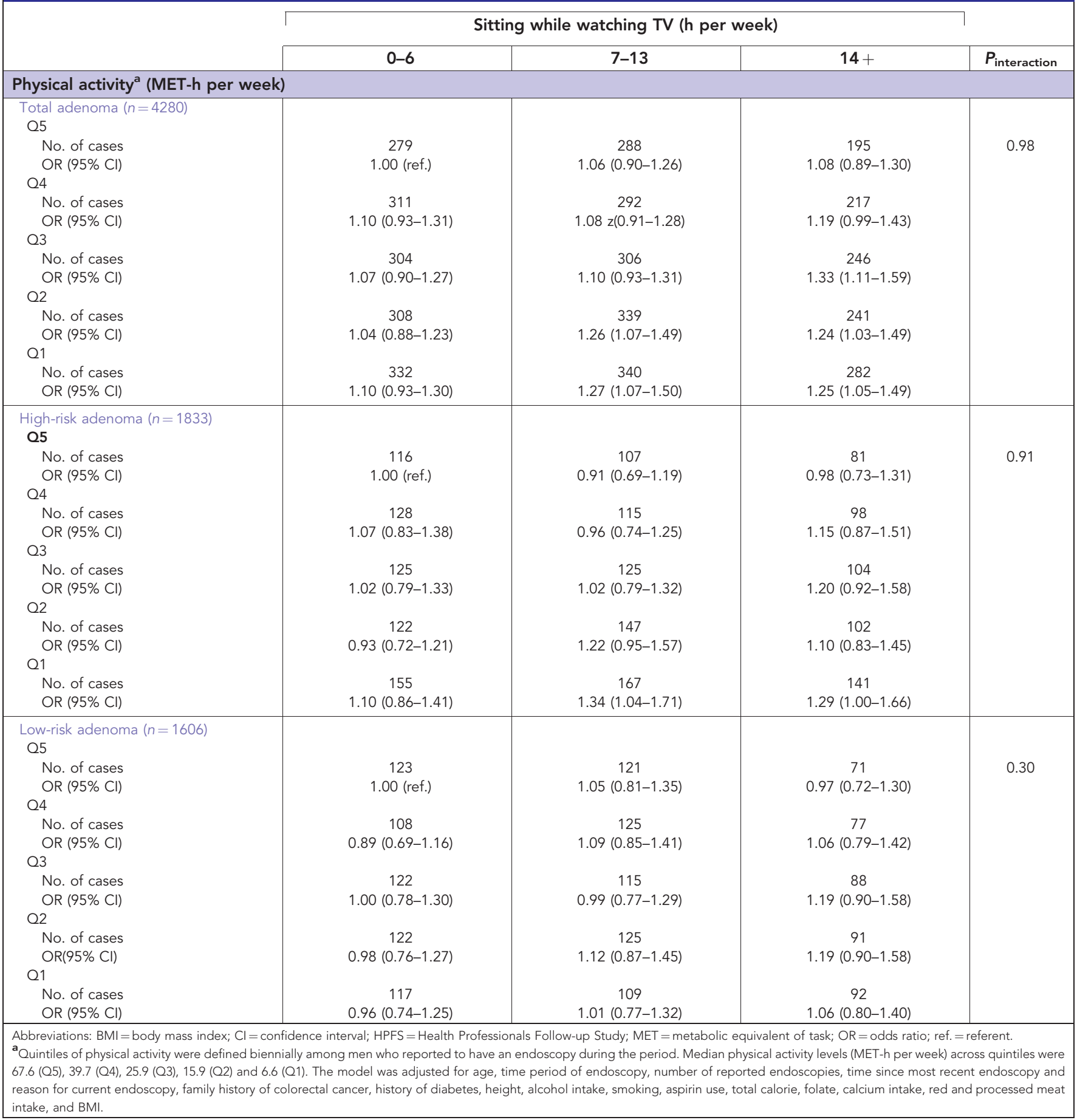

physical activity questions have been previously validated and occupational physical activities engaged by these health professionals were limited. Finally, the generalisability of our data to other populations, particularly women and other racial or ethnic groups, may be limited.

\section{CONCLUSION}

In conclusion, prolonged TV watching is associated with modest increased risk of colorectal adenoma, particularly proximal, rectal, and high-risk adenoma, independent of leisure-time physical activity and not mediated by obesity. Sedentary lifestyle may be relevant in colorectal carcinogenesis. More research is warranted to confirm our findings and studies of time spent sitting while watching TV as well as other sedentary behaviours in relation to the risk of colorectal cancer and survival among colorectal cancer patients are needed.

\section{ACKNOWLEDGEMENTS}

We thank the participants and staff of the Health Professionals Follow-Up Study for their valuable contributions as well as the following state cancer registries for their help: $\mathrm{AL}, \mathrm{AZ}, \mathrm{AR}, \mathrm{CA}$, CO, CT, DE, FL, GA, ID, IL, IN, IA, KY, LA, ME, MD, MA, MI, 
NE, NH, NJ, NY, NC, ND, OH, OK, OR, PA, RI, SC, TN, TX, VA, WA, and WY. This work was supported by grants from the NIH (P01 CA87969 to Dr Meir Stampfer; P01 CA55075 and 1UM1 CA167552 to Dr Walter Willett; R01 CA137178 and K24 DK098311 to Dr Andrew Chan) and the Entertainment Industry Foundation through the National Colorectal Cancer Research Alliance. Dr Chan is a Damon Runyon Clinical Investigator.

\section{CONFLICT OF INTEREST}

ATC reported that he has previously served as a consultant for Bayer Healthcare, Pfizer Inc., and Pozen Inc.

\section{AUTHOR CONTRIBUTIONS}

YC and ELG had full access to all of the data in the study and take responsibility for the integrity of the data and the accuracy of the data analysis. YC, KW, and ELG conceived and designed the study. KW and ELG acquired the data. YC drafted the manuscript. YC, NK, ATC, CSF, KW, and ELG critically revised the manuscript for important intellectual content. YC carried out the statistical analysis. ATC, CSF, KW, and ELG obtained funding. KW and ELG were responsible for administrative, technical, or material support. ELG was responsible for study supervision.

\section{REFERENCES}

Ainsworth BE, Haskell WL, Leon AS, Jacobs Jr DR, Montoye HJ, Sallis JF, Paffenbarger Jr RS (1993) Compendium of physical activities:

classification of energy costs of human physical activities. Med Sci Sports Exerc 25(1): 71-80.

Arbman G, Axelson O, Fredriksson M, Nilsson E, Sjodahl R (1993) Do occupational factors influence the risk of colon and rectal cancer in different ways? Cancer 72(9): 2543-2549.

Balkau B, Mhamdi L, Oppert JM, Nolan J, Golay A, Porcellati F, Laakso M, Ferrannini E (2008) Physical activity and insulin sensitivity: the RISC study. Diabetes 57(10): 2613-2618.

Boyle T, Fritschi L, Heyworth J, Bull F (2011) Long-term sedentary work and the risk of subsite-specific colorectal cancer. Am J Epidemiol 173(10): 1183-1191.

Chasan-Taber S, Rimm EB, Stampfer MJ, Spiegelman D, Colditz GA, Giovannucci E, Ascherio A, Willett WC (1996) Reproducibility and validity of a self-administered physical activity questionnaire for male health professionals. Epidemiology 7(1): 81-86.

Chow WH, Dosemeci M, Zheng W, Vetter R, McLaughlin JK, Gao YT, Blot WJ (1993) Physical activity and occupational risk of colon cancer in Shanghai, China. Int J Epidemiol 22(1): 23-29.

Curtin K, Samowitz WS, Wolff RK, Herrick J, Caan BJ, Slattery ML (2009) Somatic alterations, metabolizing genes and smoking in rectal cancer. Int J Cancer J 125(1): 158-164.

Dosemeci M, Hayes RB, Vetter R, Hoover RN, Tucker M, Engin K, Unsal M, Blair A (1993) Occupational physical activity, socioeconomic status, and risks of 15 cancer sites in Turkey. Cancer Causes Control 4(4): 313-321.

Dunstan DW, Salmon J, Healy GN, Shaw JE, Jolley D, Zimmet PZ, Owen N (2007) Association of television viewing with fasting and 2-h postchallenge plasma glucose levels in adults without diagnosed diabetes. Diabetes Care 30(3): 516-522.

Dunstan DW, Salmon J, Owen N, Armstrong T, Zimmet PZ, Welborn TA, Cameron AJ, Dwyer T, Jolley D, Shaw JE (2005) Associations of TV viewing and physical activity with the metabolic syndrome in Australian adults. Diabetologia 48(11): 2254-2261.

Edwardson CL, Gorely T, Davies MJ, Gray LJ, Khunti K, Wilmot EG, Yates T, Biddle SJ (2012) Association of sedentary behaviour with metabolic syndrome: a meta-analysis. PLoS One 7(4): e34916.

Elwing JE, Gao F, Davidson NO, Early DS (2006) Type 2 diabetes mellitus: the impact on colorectal adenoma risk in women. Am J Gastroenterol 101(8): 1866-1871.
Ford ES, Schulze MB, Kroger J, Pischon T, Bergmann MM, Boeing H (2010) Television watching and incident diabetes: findings from the European Prospective Investigation into Cancer and Nutrition-Potsdam Study. J Diabetes 2(1): 23-27.

Fung TT, Chiuve SE, McCullough ML, Rexrode KM, Logroscino G, Hu FB (2008) Adherence to a DASH-style diet and risk of coronary heart disease and stroke in women. Arch Intern Med 168(7): 713-720.

Fung TT, Hu FB, Wu K, Chiuve SE, Fuchs CS, Giovannucci E (2010) The Mediterranean and Dietary Approaches to Stop Hypertension (DASH) diets and colorectal cancer. Am J Clin Nutr 92(6): 1429-1435.

Fung TT, Hu FB, Yu J, Chu NF, Spiegelman D, Tofler GH, Willett WC, Rimm EB (2000) Leisure-time physical activity, television watching, and plasma biomarkers of obesity and cardiovascular disease risk. Am J Epidemiol 152(12): 1171-1178.

Gerhardsson M, Norell SE, Kiviranta H, Pedersen NL, Ahlbom A (1986) Sedentary jobs and colon cancer. Am J Epidemiol 123(5): 775-780.

Giovannucci E (1995) Insulin and colon cancer. Cancer Causes Control 6(2): 164-179.

Giovannucci E (2007) Metabolic syndrome, hyperinsulinemia, and colon cancer: a review. Am J Clin Nutr 86(3): s836-s842.

Giovannucci E, Ascherio A, Rimm EB, Colditz GA, Stampfer MJ, Willett WC (1995) Physical activity, obesity, and risk for colon cancer and adenoma in men. Ann Intern Med 122(5): 327-334.

Giovannucci E, Harlan DM, Archer MC, Bergenstal RM, Gapstur SM, Habel LA, Pollak M, Regensteiner JG, Yee D (2010) Diabetes and cancer: a consensus report. Cancer J Clin 60(4): 207-221.

Giovannucci E, Michaud D (2007) The role of obesity and related metabolic disturbances in cancers of the colon, prostate, and pancreas. Gastroenterology 132(6): 2208-2225.

Grontved A, Hu FB (2011) Television viewing and risk of type 2 diabetes, cardiovascular disease, and all-cause mortality: a meta-analysis. JAMA 305(23): 2448-2455.

Gustat J, Srinivasan SR, Elkasabany A, Berenson GS (2002) Relation of self-rated measures of physical activity to multiple risk factors of insulin resistance syndrome in young adults: the Bogalusa Heart Study. J Clin Epidemiol 55(10): 997-1006.

Hamilton MT, Hamilton DG, Zderic TW (2007) Role of low energy expenditure and sitting in obesity, metabolic syndrome, type 2 diabetes, and cardiovascular disease. Diabetes 56(11): 2655-2667.

Hamilton MT, Healy GN, Dunstan DW, Zderic TW, Owen N (2008) Too little exercise and too much sitting: inactivity physiology and the need for new recommendations on sedentary behavior. Curr Cardiovasc Risk Rep 2(4): 292-298.

Healy GN, Dunstan DW, Salmon J, Cerin E, Shaw JE, Zimmet PZ, Owen N (2007) Objectively measured light-intensity physical activity is independently associated with 2-h plasma glucose. Diabetes Care 30(6): 1384-1389.

Helmerhorst HJ, Wijndaele K, Brage S, Wareham NJ, Ekelund U (2009) Objectively measured sedentary time may predict insulin resistance independent of moderate- and vigorous-intensity physical activity. Diabetes 58(8): 1776-1779.

Howard RA, Freedman DM, Park Y, Hollenbeck A, Schatzkin A, Leitzmann MF (2008) Physical activity, sedentary behavior, and the risk of colon and rectal cancer in the NIH-AARP Diet and Health Study. Cancer Causes Control 19(9): 939-953.

Hu FB, Leitzmann MF, Stampfer MJ, Colditz GA, Willett WC, Rimm EB (2001) Physical activity and television watching in relation to risk for type 2 diabetes mellitus in men. Arch Intern Med 161(12): 1542-1548.

Hu FB, Li TY, Colditz GA, Willett WC, Manson JE (2003) Television watching and other sedentary behaviors in relation to risk of obesity and type 2 diabetes mellitus in women. JAMA 289(14): 1785-1791.

Krishnan S, Rosenberg L, Palmer JR (2009) Physical activity and television watching in relation to risk of type 2 diabetes: the Black Women's Health Study. Am J Epidemiol 169(4): 428-434.

Larsson SC, Orsini N, Wolk A (2005) Diabetes mellitus and risk of colorectal cancer: a meta-analysis. J Natl Cancer Inst 97(22): 1679-1687.

Lieberman DA, Rex DK, Winawer SJ, Giardiello FM, Johnson DA, Levin TR (2012) Guidelines for colonoscopy surveillance after screening and polypectomy: a consensus update by the US Multi-Society Task Force on Colorectal Cancer. Gastroenterology 143(3): 844-857.

Limsui D, Vierkant RA, Tillmans LS, Wang AH, Weisenberger DJ, Laird PW, Lynch CF, Anderson KE, French AJ, Haile RW, Harnack LJ, Potter JD, Slager SL, Smyrk TC, Thibodeau SN, Cerhan JR, Limburg PJ (2010) Cigarette smoking and colorectal cancer risk by molecularly defined subtypes. J Natl Cancer Inst 102(14): 1012-1022. 
Lynch BM (2010) Sedentary behavior and cancer: a systematic review of the literature and proposed biological mechanisms. Cancer Epidemiol Biomarkers Prev 19(11): 2691-2709.

Nielsen Company (2011) State of the Media: Trends in TV Viewing - 2011 TV Upfronts.

Nishihara R, Morikawa T, Kuchiba A, Lochhead P, Yamauchi M, Liao X, Imamura Y, Nosho K, Shima K, Kawachi I, Qian ZR, Fuchs CS, Chan AT, Giovannucci E, Ogino S (2013) A prospective study of duration of smoking cessation and colorectal cancer risk by epigenetics-related tumor classification. Am J Epidemiol 178(1): 84-100.

Owen N, Healy GN, Matthews CE, Dunstan DW (2010) Too much sitting: the population health science of sedentary behavior. Exerc Sport Sci Rev 38(3): 105-113.

Pinto Pereira SM, Ki M, Power C (2012) Sedentary behaviour and biomarkers for cardiovascular disease and diabetes in mid-life: the role of televisionviewing and sitting at work. PLoS One 7(2): e31132.

Poynter JN, Haile RW, Siegmund KD, Campbell PT, Figueiredo JC, Limburg P, Young J, Le Marchand L, Potter JD, Cotterchio M, Casey G, Hopper JL, Jenkins MA, Thibodeau SN, Newcomb PA, Baron JA (2009) Associations between smoking, alcohol consumption, and colorectal cancer, overall and by tumor microsatellite instability status. Cancer Epidemiol Biomarkers Prev 18(10): 2745-2750.

Regula J, Rupinski M, Kraszewska E, Polkowski M, Pachlewski J, Orlowska J, Nowacki MP, Butruk E (2006) Colonoscopy in colorectal-cancer screening for detection of advanced neoplasia. N Engl J Med 355(18): 1863-1872.

Rimm EB, Stampfer MJ, Colditz GA, Giovannucci E, Willett WC (1990) Effectiveness of various mailing strategies among nonrespondents in a prospective cohort study. Am J Epidemiol 131(6): 1068-1071.

Robsahm TE, Aagnes B, Hjartaker A, Langseth H, Bray FI, Larsen IK (2013) Body mass index, physical activity, and colorectal cancer by anatomical subsites: a systematic review and meta-analysis of cohort studies. Eur J Cancer Prev 22(6): 492-505.

Rozek LS, Herron CM, Greenson JK, Moreno V, Capella G, Rennert G, Gruber SB (2010) Smoking, gender, and ethnicity predict somatic BRAF mutations in colorectal cancer. Cancer Epidemiol Biomarkers Prev 19(3): 838-843.

Samowitz WS, Albertsen H, Sweeney C, Herrick J, Caan BJ, Anderson KE, Wolff RK, Slattery ML (2006) Association of smoking, CpG island methylator phenotype, and V600E BRAF mutations in colon cancer. J Natl Cancer Inst 98(23): 1731-1738.
Schmid D, Leitzmann MF (2014) Television viewing and time spent sedentary in relation to cancer risk: a meta-analysis. J Natl Cancer Inst 106(7): pii: dju098.

Schmidt MD, Cleland VJ, Thomson RJ, Dwyer T, Venn AJ (2008) A comparison of subjective and objective measures of physical activity and fitness in identifying associations with cardiometabolic risk factors. Ann Epidemiol 18(5): 378-386.

Slattery ML, Curtin K, Anderson K, Ma KN, Ballard L, Edwards S, Schaffer D, Potter J, Leppert M, Samowitz WS (2000) Associations between cigarette smoking, lifestyle factors, and microsatellite instability in colon tumors. J Natl Cancer Inst 92(22): 1831-1836.

Stamatakis E, Hamer M, Dunstan DW (2011) Screen-based entertainment time, all-cause mortality, and cardiovascular events: population-based study with ongoing mortality and hospital events follow-up. J Am Coll Cardiol 57(3): 292-299.

Wang Y, Jacobs EJ, Patel AV, Rodriguez C, McCullough ML, Thun MJ, Calle EE (2008) A prospective study of waist circumference and body mass index in relation to colorectal cancer incidence. Cancer Causes Control 19(7): 783-792.

Wannamethee SG, Shaper AG, Lennon L, Whincup PH (2007) Decreased muscle mass and increased central adiposity are independently related to mortality in older men. Am J Clin Nutr 86(5): 1339-1346.

Warren TY, Barry V, Hooker SP, Sui X, Church TS, Blair SN (2010) Sedentary behaviors increase risk of cardiovascular disease mortality in men. Med Sci Sports Exerc 42(5): 879-885.

Weiderpass E, Vainio H, Kauppinen T, Vasama-Neuvonen K, Partanen T, Pukkala E (2003) Occupational exposures and gastrointestinal cancers among Finnish women. J Occup Environ Med 45(3): 305-315.

Wijndaele K, Brage S, Besson H, Khaw KT, Sharp SJ, Luben R, Wareham NJ, Ekelund U (2011) Television viewing time independently predicts all-cause and cardiovascular mortality: the EPIC Norfolk study. Int J Epidemiol 40(1): 150-159.

Winawer SJ, Zauber AG (2002) The advanced adenoma as the primary target of screening. Gastrointest Endosc Clin N Am 12(1): 1-9, v.

This work is published under the standard license to publish agreement. After 12 months the work will become freely available and the license terms will switch to a Creative Commons AttributionNonCommercial-Share Alike 4.0 Unported License.

Supplementary Information accompanies this paper on British Journal of Cancer website (http://www.nature.com/bjc) 